10.1117/2.1200909.1738

\title{
Electroactive polymers for refreshable Braille displays
}

\section{Yoseph Bar-Cohen}

Arrays of actuated dots may one day produce refreshable Braille that allows the visually impaired to read a full screen of electronic text.

According to the World Health Organization, about 314 million people are visually impaired, with 45 million blind. To benefit from state-of-the-art digital technology and the many emerging computer-controlled devices, these individuals need efficient and inexpensive refreshable full-page Braille displays. This would provide them effective ways to rapidly exchange information (e.g., e-mail and text messaging), as well as providing access to the plethora of information on the Web and other forms of electronic databases and archives (e.g., educational, employment, and recreational opportunities).

The raised dots of Braille code-developed by the 16-year old Louis Braille in 1825-had a dramatic impact on blind people's ability to read and write. Braille (whose bicentennial birthday is celebrated this year) simplified the 12 raised-dot code of Captain Charles Barbier, who initially created a system to enable Napoleon's army to communicate silently at night. Braille's system used only six dots per character, arranged in a rectangular shape along two columns of three each: see Figure 1(a). This modification made the code much easier for fingertips to sense through touch and led to significantly faster reading. A later version uses eight dots with two rows of four dots, increasing the possible combination of signs from 64 to 256: see Figure 1(b). This code represents all printable American Standard Code for Information Interchange (ASCII) characters in a single cell. ${ }^{1}$

In contrast to the hardcopy form, a refreshable Braille display needs to raise and lower a large array of dense dots, allowing quick tactile perception for rapid reading. Such tactile displays may include single character presentation devices, single line units, and full-page presentation boards filled with characters. (Commercial active Braille devices are limited to single characters and line displays.) Producing a full-page Braille display requires packing many small actuated dots (diameter about $1.65 \mathrm{~mm})$ in a small, closely spaced arrangement, raising the
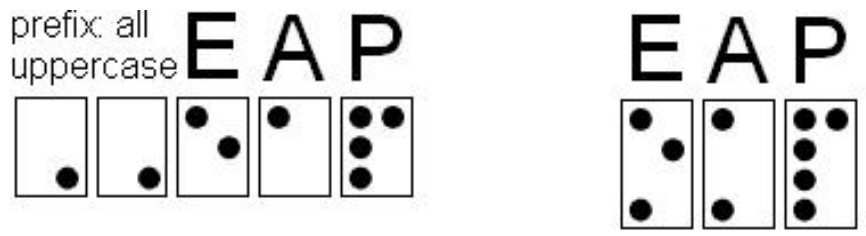

Figure 1. The acronym EAP in upper case expressed in the six and eight dot Braille code systems. ${ }^{1}$

height to approximately $0.5 \mathrm{~mm}$, and an actuation force of at least $0.15 \mathrm{~N}^{2,3}$ A standard Braille page is $28 \mathrm{~cm} \times 30 \mathrm{~cm}$ and has room for 25 lines of 40 characters each-which requires 6,000 to 8,000 dots. The small dimensions, the complexity of producing a reliable display that withstands daily wear and tear, and the small market make such active displays quite costly and challenging to develop.

Constraining the active display to one cell takes care of the size issue, but the disadvantage is that the user's finger cannot brush across the Braille cell. Instead, the finger rests on the refreshable Braille cell, a departure from the user's usual reading habit. Generally, prototypes and commercial products are electro-mechanical devices that raise dots through holes in a flat surface. Over the years, researchers developed and tested various actuators and mechanisms, such as electromagnetic, piezoelectric, thermal, pneumatic, and shape memory alloys. ${ }^{4}$

In recent years, many electroactive polymer (EAP) materials have emerged with the potential to enable active, full-page displays. ${ }^{5,6}$ The key benefit of these materials is that they are increasingly enabling researchers to pack many actuators into a small area without interference. Pioneering these efforts, I conceived a refreshable Braille display in 1998 (see Figure 2). 5,7 The concept is based on using a field-activated type EAP actuator configured in an array form. Rows of electrodes on one side of an EAP film and columns on the other activate individual elements in the array. Each element is mounted with a Braille dot and is lowered by applying a voltage across the thickness of the

Continued on next page 


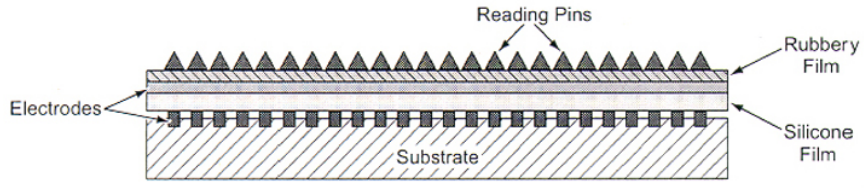

CROSS SECTION OF DEVICE

Column Electrodes on Top of Substrate
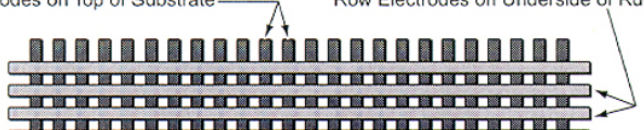

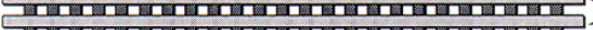

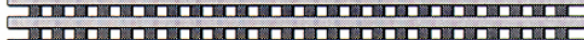





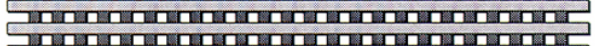



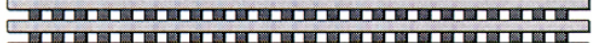

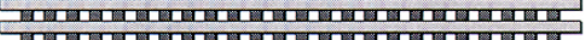

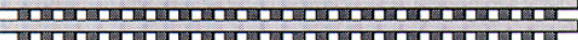

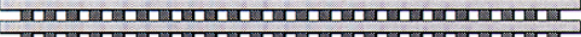

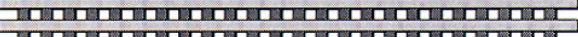

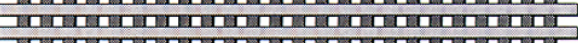
Inrmm

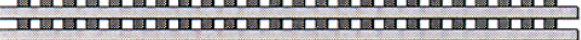
Fon

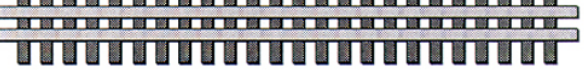
ELECTRODE PATTERN

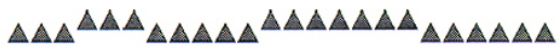

PARTIAL CROSS SECTION SHOWING READING PINS LOWERED SELECTIVELY TO DISPLAY INFORMATION

Figure 2. An EAP film with addressable dots at the intersection between selected row and column electrodes to which voltage is applied. $^{5,7}$

selected element, causing local thickness reduction. Under computer control, dots would be activated to create tactile patterns of highs and lows representing the information to be read. A person would read by scanning with the fingertips, as in reading conventional Braille print. I also envisioned the possibility of presenting graphics to view illustrations or the road ahead.

Since 2003, several groups have reported development of active Braille prototypes using EAP-based actuators, including Wollongong University jointly with Quantum Technologies in Sydney, Australia, ${ }^{8}$ Darmstadt University of Technology in Germany, ${ }^{3}$ (see a demonstration online ${ }^{9}$ ) the University of Tokyo, the National Institute of Advanced Industrial Science and Technology (AIST) in Osaka, Japan, ${ }^{2}$ Sungkyunkwan University in the Republic of Korea, ${ }^{10}$ as well as Pennsylvania State University, ${ }^{11}$ SRI International ${ }^{12}$ (see video ${ }^{13}$ ), and Carolina State University. ${ }^{14}$ The researchers used materials such as conducting polymers, dielectric elastomers, ferroelectric, ionic polymer metal composite (IPMC), and polyvinylidene difluoride (PVDF). These were chosen since (of known EAP materials ${ }^{5}$ ) they are the most ready for use in applications. The ionic EAP materials (conductive polymers and IPMC) are attractive for their low activation voltage while

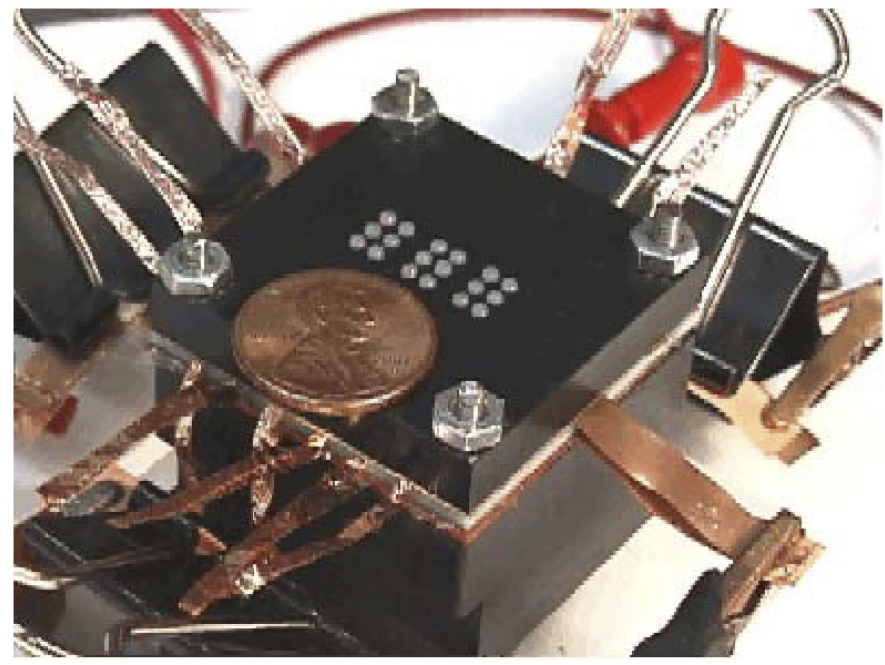

Figure 3. SRI International's dielectric elastomer diaphragm-based prototype. Thin metal traces activate individual dots. It combines pressurized air and dots of diameter $1.6 \mathrm{~mm}$ activated by $5.68 \mathrm{kV}$, producing displacement of $450 \mu \mathrm{m}$. Courtesy of Richard Heydt, SRI International, ${ }^{12}$ with permission of the Society for Information Display.

the field-activated ones (dielectric elastomer ferroelectric, and PVDF) generate a larger actuation force. These research efforts focus on developing miniature actuated pins/dots that can be packed into a small area while still generating sufficient displacement and force. The actuators are made to expand in an array form or to move levers. They are designed in various configurations including a film that is rolled around a pre-strained spring, a bimorph configuration, shaped as a multi-layered array, or consisting of a pre-strained diaphragm with a series of spring-backed elements. Figures 3 and 4 show examples of these devices.

While these displays are close to performing at the required specifications, challenges still limit their commercially viability. Future work should focus on the need for low activation voltage when using field-activated EAP, as well as the insufficient force in the case of IPMC, and the short cycling life of the conducting polymers. Also, there are challenges related to their reliable operation and mass-production limitations. Advances in developing more effective materials and processing techniques may lead to practical, low-cost, compact Braille displays.

Recently, the Center for Braille Innovation (of the Bostonbased National Braille Press) contacted me in an effort to start collaboration with researchers towards accelerating the

Continued on next page 


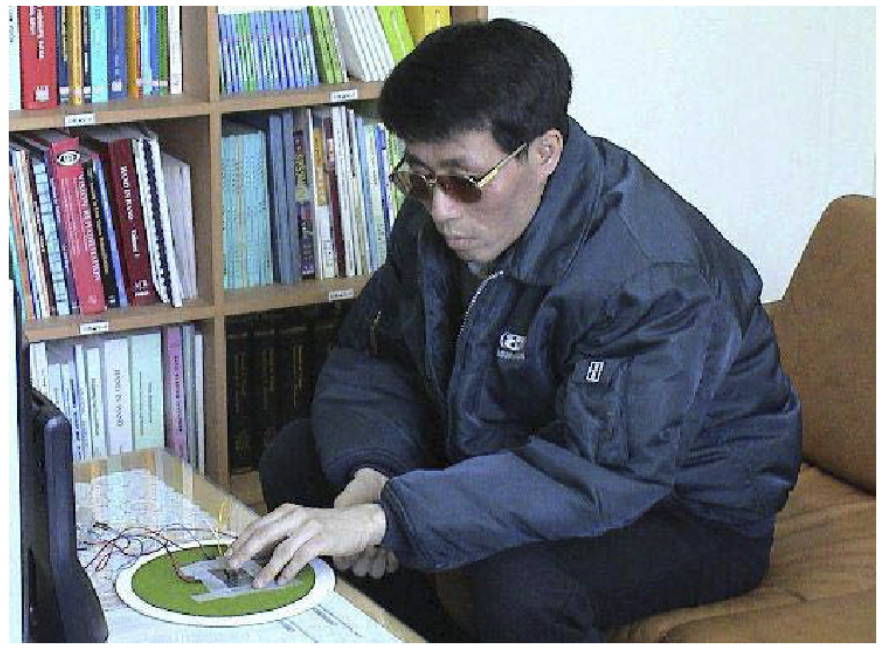

Figure 4. A blind person uses the dielectric elastomer EAP-based refreshable Braille display developed at Sungkyunkwan University. Courtesy of HR Choi, Sungkyunkwan University. ${ }^{10}$

development of EAP-actuated active Braille displays. Since these actuators have other applications as well-such as operating haptic/tactile interfaces ${ }^{15}$ and displays for interaction with or through computers-I initiated a special session on this topic as part of the SPIE Electroactive Polymer Actuators and Devices Conference (scheduled for March 9, 2010 in San Diego, CA). A call for abstracts and demos (for the EAP-in-Action Session) was announced to provide a forum for highlighting the latest developments. ${ }^{16}$ The market for haptic/tactile interfaces (see video ${ }^{17}$ ) and displays is growing rapidly, and they are used in teleoperators and simulators, computer interfaces and video games (e.g., joysticks and the Wii game console), robotics, touch screens, tactile displays, surgical force-feedback devices, and other devices.

Some of this research was conducted at the Jet Propulsion Laboratory, California Institute of Technology, under a contract with NASA.

\section{Author Information}

\section{Yoseph Bar-Cohen}

Advanced Technologies Group

NASA Jet Propulsion Laboratory

Pasadena, CA

http://ndeaa.jpl.nasa.gov/nasa-nde/yosi/yosi.htm

http:/ /ndeaa.jpl.nasa.gov
Yoseph Bar-Cohen is a senior research scientist and group supervisor. He received his $\mathrm{PhD}$ in physics (1979) from the Hebrew University, Israel. He has coauthored over 330 publications and presented numerous papers. He holds 19 patents, has coedited and coauthored 6 books, and has chaired 38 conferences and symposia. His is a SPIE Fellow and an American Society for Nondestructive Testing fellow. He has earned many awards including two NASA Honor Medals and two SPIE Lifetime Achievement Awards.

\section{References}

1. N. Runyan, personal e-mail communication with the author, May 2009.

2. Y. Kato, T. Sekitani, M. Takamiya, M. Doi, K. Asaka, T. Sakurai, and T. Someya, Sheet-type Braille displays by integrating organic field-effect transistors and polymeric actuators, IEEE Trans. Electron Dev. 54 (2), pp. 202-209, 2007.

3. M. Matysek, P. Lotz, and H. F. Schlaak, Tactile display with dielectric multilayer elastomer actuators, Proc. SPIE 7287, p. 72871D, 2009. doi:10.1117/12.819217

4. N. Runyan and E. Nassimbene, Alphanumeric "displays" for the blind: A technology search Tech. Rep. pp. 1-33, International Business Machines (IBM) Corporation, Los Gatos, CA, 1974.

5. Y. Bar-Cohen ed., Electroactive Polymer (EAP) Actuators as Artificial Muscles - Reality, Potential and Challenges, 2nd ed. PM136, pp. 1-765, SPIE Press, Bellingham, WA, 2004

6. http://mfile.akamai.com/65904/mov/spiestorage.download.akamai.com/ 65904/Newsroom/OP09/Yoseph.mov The author discusses EAP history and evolution.

7. Y. Bar-Cohen, Active reading display for blind (ARDIB) Tech. Rep. 0008b, Docket 20410, NASA, Pasadena, CA, 2001.

8. G. M. Spinks and G. G. Wallace, Biomedical Applications of Electroactive Polymer Actuators, ch. Actuated pins for braille displays, John Wiley \& Sons Ltd. Chichester, UK, 2009.

9. http://www.emk.tu-darmstadt.de/institut/fachgebiete/m_ems/forschung/ dielektrische_polymeraktoren/taktile_displays/Multilayer structure of stack actuator made of dielectric elastomer EAP. Courtesy of Helmut F. Schlaak, Darmstadt University of Technology, Germany. Accessed 25 August 2009.

10. H. R. Choi, I. M. Koo, K. Jung, S.-G. Roh, J. C. Koo, J.-D. Nam, and Y. K. Lee, Biomedical Applications of Electroactive Polymer Actuators, ch. A Braille display system for the visually disabled using polymer based soft actuator, John Wiley \& Sons, Ltd., Chichester, UK, 2009.

11. K. Ren, S. Liu, M. Lin, Y. Wang, and Q. M. Zhang, A compact electroactive polymer actuator suitable for refreshable Braille display, Sens. Actuators A: Phys. 143 (2), pp. 335-342, 2008.

12. R. Heydt and S. Chhokar, Refreshable Braille display based on electroactive polymers, Proc. Int'1 Display Res. Conf. P7.5, 2003.

13. http://spie.org/documents/newsroom/videos/1738/SRI_Brailleprototype_Squares-lines.MPG Braille prototype demo developed at SRI International using diaphragm made of dielectric elastomer EAP. Courtesy of Richard Heydt, SRI International.

14. N. Di Spigna, P. Chakraborti, P. Yang, T. Ghosh, and P. Franzon, Application of EAP materials toward a refreshable Braille display, Proc. SPIE 7287, p. 72871K, 2009. doi:10.1117/12.816009

15. F. Carpi, G. Frediani, and D. De Rossi, Hydrostatically coupled dielectric elastomer actuators, IEEE/ASME Trans. Mechatron., 2009. To be published

16. http://spie.org/app/program/index.cfm?fuseaction=conferencedetail\&conference _id=896956\&event_id=894245 Call for Abstracts for the EAP-In-Action Session.

17. http://spie.org/documents/newsroom/videos/1738/Pisa-HCDE.mov Array of hydrostatically coupled dielectric elastomer actuators for possible tactile interface. Courtesy of Federico Carpi, University of Pisa, Italy. 